\title{
Morphological differentiation between rejection and cyclosporin nephrotoxicity in renal allografts
}

\author{
GH NEILD, DHTAUBE, RB HARTLEY, LBIGNARDI, JS CAMERON, \\ DG WILLIAMS, CS OGG, CJ RUDGE
}

From the Renal Unit and Department of Pathology, Guy's Hospital, London

SUMMARY In a prospective study of renal dysfunction in 60 consecutive allograft recipients treated with cyclosporin and prednisolone routine renal biopsies at one week and one month after transplantation, as well as for all episodes of renal dysfunction, were performed. The one year graft survival of this group was $88 \%$.

In a retrospective clinical analysis of these patients 35 episodes of dysfunction due to rejection, defined by a response to antirejection treatment alone, and 30 episodes due to cyclosporin nephrotoxicity, defined by a response to reduction in cyclosporin dose alone, were identified. The morphological findings from these biopsies were compared with 20 samples from routine biopsies taken from patients with stable renal function. All patients diagnosed as having rejection had a diffuse, interstitial mononuclear cell infiltrate (32 of 35) or arteritis (19 of 35), or both. In contrast, focal mononuclear cell infiltrates were common in both patients with nephrotoxicity and those with stable function (17 of 30 and 14 of 20 , respectively). There were no important differences between biopsies from those with nephrotoxicity and those with stable function, except that arteriolar hyalinosis was considerably more common in the nephrotoxic patients than in those with stable function. Many patients with stable function were, in retrospect, in a state of stable mild nephrotoxicity.

In our experience rejection should only be diagnosed when there is at least a diffuse interstitial infiltrate or an arteritis. Focal mononuclear cell infiltrates do not denote rejection. The development of arteriolar lesions in the absence of rejection is indicative of nephrotoxicity.

The advent of cyclosporin heralded a major advance in the success of organ transplantation. Its use, however, has been complicated by nephrotoxicity, and this has been a particular problem in renal transplantation. $^{1-3}$

It was hoped that renal biopsy would enable rejection and nephrotoxicity to be distinguished, but preliminary morphological studies by several groups found that there were no simple answers. ${ }^{45}$ In particular, cellular infiltration of the graft was difficult to interpret. Diffuse mononuclear cell infiltrate and oedema were indicative of rejection, but large foci of mononuclear cells could be found during periods of either stable function or cyclosporin nephrotoxicity. ${ }^{45}$ Mihatsch et al suggested that tubular necrosis, vacuolisation, and calcification were more

Accepted for publication 29 October 1985 common in nephrotoxicity, ${ }^{6}$ but others found these features to be poor discriminators. ${ }^{5}$ In addition, Mihatsch also described an arteriolar lesion that seems to be associated with cyclosporin toxicity. ${ }^{67}$

When we started to use cyclosporin instead of azathioprine for our transplantation immunosuppression we began a prospective study, the aim of which was to distinguish renal dysfunction due to cyclosporin nephrotoxicity from rejection. We accordingly biopsied all renal allografts routinely one week, one month, and one year after transplantation, and during all episodes of deteriorating renal function. We were therefore able to compare dysfunctioning with functioning allografts for the first time. In this paper we report the morphological findings of 122 biopsy specimens from 60 consecutive renal allograft recipients. We emphasise the incidence of focal cellular infiltrates in grafts with good function and the importance of vessel lesions as indicators of cyclosporin toxicity. 


\section{Reflection or cyclosporin nephrotoxicity in renal allografts}

\section{Patients and methods}

Sixty patients (mean age 43.7 years; range 15 to 72 years) were studied. Three received their allograft from a live related donor. Forty nine received their first allograft, seven their second, and four their third. Blood transfusion and histocompatability details have already been reported. ${ }^{8}$ The age and cause of death of cadaver donors were recorded.

Cyclosporin (Sandimmun, Sandoz) was given orally as a single daily dose in the following regimen: $14 \mathrm{mg} / \mathrm{kg} /$ day for 14 days, then $12 \mathrm{mg} / \mathrm{kg} /$ day until day $30,10 \mathrm{mg} / \mathrm{kg} /$ day until day $60,8 \mathrm{mg} / \mathrm{kg} /$ day until day 90 , and then $6 \mathrm{mg} / \mathrm{kg} /$ day. Prednisolone was given orally at a starting dose of $15 \mathrm{mg} / \mathrm{m}^{2}$ tapering to a dose of $7.5 \mathrm{mg} / \mathrm{m}^{2}$ at 12 months. Whole blood cyclosporin concentrations $(\mu \mathrm{g} / \mathrm{l})$ were measured by radioimmunoassay using the Sandoz radioimmunoassay kit. Cyclosporin was given at $6.00 \mathrm{pm}$, and whole blood concentrations were measured the following morning. Renal function (plasma urea and creatinine), plasma biochemistry, and haematological indices were monitored as previously described. ${ }^{89}$

Renal dysfunction (in functioning allografts) was defined as a decrease in renal function, or a decline in rate of improvement of renal function during the three days before biopsy. Allografts that did not function immediately after transplantation were defined as having delayed primary function.

Episodes of dysfunction, which were considered to be due to rejection, were treated with intravenous pulses of $1 \mathrm{~g}$ of methylprednisolone on three consecutive days. When rejection was associated with prominent vascular injury (vascular rejection) patients were also treated with a nine day course of antilymphocyte globulin ("Pressimmune," Hoechst). Episodes of dysfunction, which were thought to be due to nephrotoxicity, were treated by a reduction in the dose of cyclosporin of $2 \mathrm{mg} / \mathrm{kg} /$ day every five days, or initially $1 \mathrm{mg} / \mathrm{kg}$ every three days.

In this analysis we defined rejection and nephrotoxicity retrospectively, as episodes of renal dysfunction or delayed primary function that responded to the appropriate treatment within 10 days. Patients were defined as having stable function if function remained constant or improved in the three days before and ten days after biopsy. Patients who did not fall within these strict definitions or who received treatment both for rejection and toxicity were excluded from this analysis.

Renal biopsies were performed routinely after one week, one month, one year, and for episodes of renal dysfunction. Biopsies were performed using a modified Vim-Silverman needle. Part of the specimen was fixed in $10 \%$ neutral phosphate buffered formol saline, embedded in paraffin wax, and processed for light microscopy, as previously described ${ }^{8}$ Sections ( 2 to $4 \mu \mathrm{m}$ thick) were stained with haematoxylin and eosin, periodic acid schiff, Martius scarlet blue, elastic van Gieson, and methenamine silver. Paraffin embedded sections were also processed for immunoperoxidase using the peroxidase-antiperoxidase (PAP) method. ${ }^{8}$ Stained sections were coded and examined blind. The following morphological features were examined:

Glomeruli Mesangial cell proliferation; mesangial matrix increase; mononuclear cells, and polymorphonuclear cells inside capillary loops; capillary thrombosis; evidence of glomerular ischaemia (from wrinkling of basement membrane to collapse of glomerular tuft).

Arterioles Endothelial cell proliferation; endothelial cell vacuolisation; intimal hypertrophy; medial hypertrophy; medial cell vacuolisation; hyalinosis; fibrinoid necrosis; intimal fibrosis and obliteration of lumen. Arteries The same definitions as for arterioles plus mononuclear cell infiltration of the vessel wall.

Tubules Vacuolisation; necrosis of tubular cells; calcification in tubular lumina; leucocyte casts; red cell casts; tubular dilatation or atrophy, or both; tubular infarction.

Interstitium Mononuclear cell infiltration was classified as either focal, or diffuse, or focal and diffuse; interstitial haemorrhage; oedema; fibrosis; mononuclear cells confined to peritubular capillaries ("tubulitis").

Morphological features were scored on a semiquantitative scale: $0=$ none, $1=\operatorname{mild}, 2=\bmod$ erate, $3=$ severe. A total of 122 biopsies were available for study. Biopsies were considered to be adequate if they contained at least three glomeruli. Statistical analyses were performed using the $\chi^{2}$ test with the Yates correction.

\section{Results}

\section{CLINICAL}

The clinical details of this study have already been reported. The actuarial one year graft survival of this group was $88 \% .^{8}$ The mean plasma creatinine concentration at six months was 157 ((SD) $100 \mathrm{umol} / \mathrm{l}$ ) (mean (2SD)). Three groups of patients were identified: 35 with rejection, 30 with nephrotoxicity, 20 with stable renal function. The biopsies for rejection were performed at a mean time after transplantation of $14.9(2.7)$ days (mean (SEM)) and a median time of seven days: for nephrotoxicity-mean time 34 (6.8) days, median 26 days; routine biopsies with stable function - that is, after one week and one month (mean 20 (3.5) days.) The mean creatinine concentration of the group with stable function was 191 (110) $\mu \mathrm{mol} / \mathrm{l}$ at the time of biopsy. In the entire group 
Table 1 Glomeruli

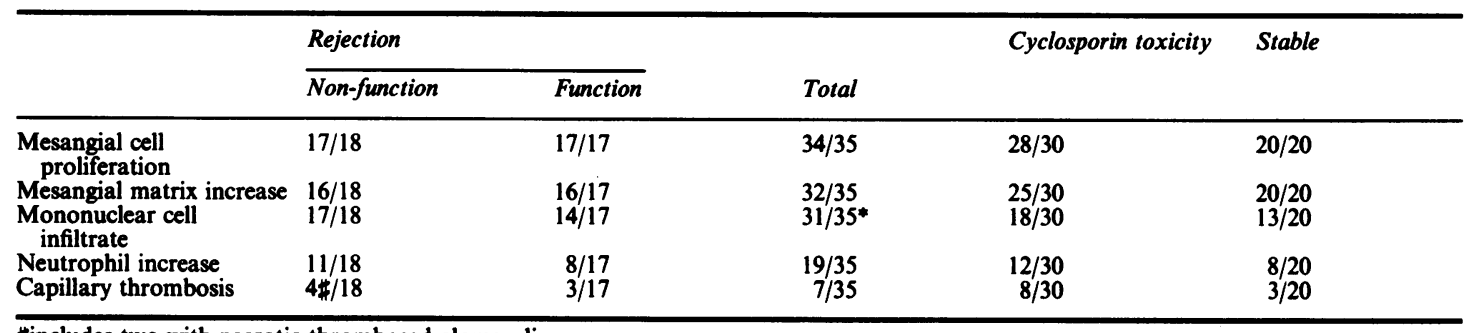

\#includes two with necrotic thrombosed glomeruli.

${ }^{*} p<0.05$, when rejection is compared with cyclosporin toxicity only.

Table 2 Arterioles

\begin{tabular}{llccc}
\hline & Rejection & & Cyclosporin toxicity & Stable \\
\cline { 2 - 5 } & Non-function & Function & Total & \\
\hline $\begin{array}{l}\text { Endothelial cell } \\
\begin{array}{l}\text { proliferation } \\
\text { Endothelial cell }\end{array}\end{array}$ & $14 / 18$ & $15 / 17$ & $29 / 35 *$ & $16 / 30$ \\
$\begin{array}{l}\text { vacuolisation } \\
\text { Medimal hypertrophy }\end{array}$ & $13 / 18$ & $9 / 17$ & $22 / 35$ & $16 / 30$ \\
$\begin{array}{l}\text { Medial hypertrophy } \\
\text { Medial hycuolisation }\end{array}$ & $11 / 18$ & $8 / 17$ & $11 / 35$ & $18 / 30$ \\
\hline
\end{tabular}

* $p<0.05$, when compared with the other two groups individually.

Table 3 Arteries

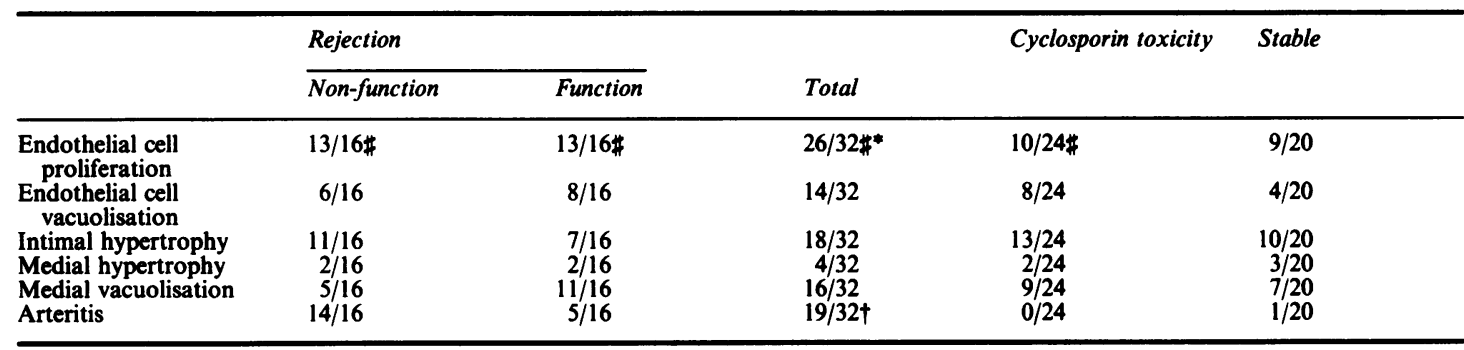

* number of biopsies containing arteries.

${ }^{*} \mathrm{p}<0.05,+\mathrm{p}<0.001$, when compared with the other two groups individually.

Table 4 Tubules

\begin{tabular}{|c|c|c|c|c|c|}
\hline & \multicolumn{2}{|l|}{ Rejection } & \multirow[b]{2}{*}{ Total } & \multirow[t]{2}{*}{ Cyclosporin toxicity } & \multirow[t]{2}{*}{ Stable } \\
\hline & Non-function & Function & & & \\
\hline $\begin{array}{l}\text { Vacuolisation } \\
\text { Necrosis } \\
\text { Calcification } \\
\text { Casts } \\
\text { Red cell casts } \\
\text { Tubular dilatation or } \\
\text { atrophy, or both }\end{array}$ & $\begin{array}{r}13 / 18 \\
18 / 18 \\
1 / 18 \\
11 / 18 \\
8 / 18 \\
12 / 18\end{array}$ & $\begin{array}{r}16 / 17 \\
12 / 17 \\
0 / 17 \\
13 / 17 \\
5 / 17 \\
11 / 17\end{array}$ & $\begin{array}{l}29 / 35 \\
30 / 35 \\
1 / 35 \\
24 / 35 \\
13 / 35 \\
23 / 35\end{array}$ & $\begin{array}{r}22 / 30 \\
25 / 30 \\
0 / 30 \\
10 / 30 \\
2 / 30 \\
11 / 30\end{array}$ & $\begin{array}{l}14 / 20 \\
16 / 20 \\
1 / 20 \\
4 / 20 \\
0 / 20 \\
8 / 20\end{array}$ \\
\hline
\end{tabular}

$\# p<0.01$, when compared with the other two groups individually.

the plasma creatinine concentration later fell after further routine reductions of the dose of cyclosporin; at six months their mean creatinine concentration was $134(80) \mu \mathrm{mol} / \mathrm{l}$.

Thirty seven biopsies with adequate material were omitted from the study for the following reasons: twelve had no response to methylprednisolone; five had no response to cyclosporin reduction; seven were treated both with methylprednisolone and cyclosporin reduction; five had spontaneous im- 
Table 5 Interstitium

\begin{tabular}{|c|c|c|c|c|c|}
\hline & \multicolumn{2}{|l|}{ Rejection } & \multirow[b]{2}{*}{ Total } & \multirow[t]{2}{*}{ Cyclosporin toxicity } & \multirow[t]{2}{*}{ Stable } \\
\hline & Non-function & Function & & & \\
\hline $\begin{array}{l}\text { Focal infiltrate } \\
\text { Diffuse infiltrate } \\
\text { Focal and diffuse } \\
\text { infiltrate }\end{array}$ & $\begin{array}{l}2 / 18 \\
7 / 18 \\
9 / 18\end{array}$ & $\begin{array}{l}1 / 17 \\
9 / 17 \\
7 / 17\end{array}$ & $\begin{array}{r}3 / 35 \dagger \\
16 / 35 \dagger \\
16 / 35^{*}\end{array}$ & $\begin{array}{r}18 / 30 \\
1 / 30 \\
4 / 30\end{array}$ & $\begin{array}{r}14 / 20 \\
0 / 20 \\
2 / 20\end{array}$ \\
\hline $\begin{array}{l}\text { Interstitial haemorrhage } \\
\text { Oedema } \\
\text { Fibrosis } \\
\text { Tubulitis }\end{array}$ & $\begin{array}{r}9 / 18 \\
18 / 18 \\
2 / 18 \\
3 / 18\end{array}$ & $\begin{array}{r}4 / 17 \\
12 / 17 \\
4 / 17 \\
6 / 17\end{array}$ & $\begin{array}{l}13 / 35 \dagger \\
30 / 35 \dagger \\
6 / 35 \\
9 / 35\end{array}$ & $\begin{array}{l}0 / 30 \\
4 / 30 \\
9 / 30 \\
2 / 30\end{array}$ & $\begin{array}{l}0 / 20 \\
6 / 20 \\
7 / 20 \\
2 / 20\end{array}$ \\
\hline
\end{tabular}

$\dagger \mathrm{p}<0.001,{ }^{*} \mathrm{p}<0.02$, when compared with the other two groups individually.

provement; seven had spontaneous deterioration; one had a ureteric obstruction.

\section{MORPHOLOGICAL}

Tables 1-5 show the morphological findings in the three groups. The morphological findings were considered firstly with reference to the different structures, and, secondly, with reference to the differential diagnosis.

\section{Glomeruli}

A few (score 1) mononuclear cells (1-10/glomerulus) and polymorphs (1-5/glomerulus) were commonly found in all three patient groups. Glomeruli containing 10 or more mononuclear cells (score 2 or more) were exclusively confined to those patients with rejection.

In two biopsies with severe vascular rejection there was glomerular thrombosis and infarction with fibrin

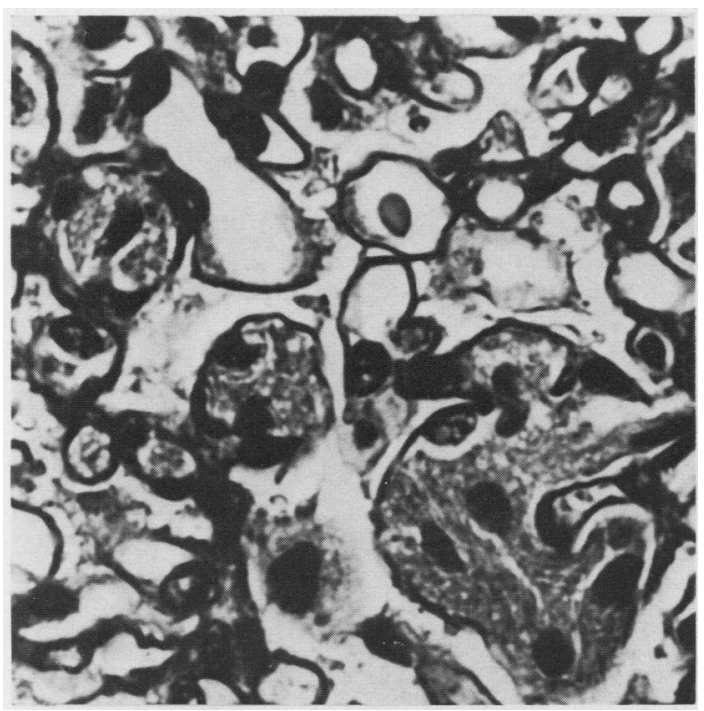

Fig. 1 Glomerular capillaries are partly occluded by finely granular material associated with mononuclear cells. (Periodic acid Schiff.) $\times 510$. like material occluding the lumina. In a further 16 biopsies from all three groups we saw a different type of capillary thrombosis characterised by finely granular material partially obstructing glomerular capillaries (Table 1). The staining characteristics of these thrombi were compatible with platelet/fibrin aggregates, and this was confirmed by immunoperoxidase examination. ${ }^{9}$ This granular material was typically associated with one or more phagocytic mononuclear cells (Fig. 1).

\section{Arterioles}

In many patients receiving cyclosporin we noted arteriolar changes that were out of proportion to the age of the donor, the blood pressure of the recipient, and which occurred in the absence of evidence of rejection.

The earliest changes were of a mucoid appearance of the medial cells, with loss of both the periodic acid Schiff positive staining of cells and clear definition of the cell architecture. There was hypertrophy of medial cells and the thickness of the arteriolar wall was often asymmetrical. The arterioles seemed to be vasoconstricted. Vacuolisation of the medial cells occurred (Fig. 2). Later, there was a hyalinosis of the media which was strongly periodic acid Schiff positive (Figs. 2 and 3). Endothelial cells were prominent (hypertrophy and hyperplasia) and sometimes occluded the vessel lumen (Fig. 2). This prominence was termed in our analysis as "endothelial cell proliferation." Arteriolar hyalinosis was found in all groups but was considerably more common in those with nephrotoxicity compared with those with rejection. Prominent hyalinosis (score 2 or more) was found in 13 of 30 in the group with nephrotoxicity compared with seven and three in the groups with rejection and stable groups, respectively, but this increase did not quite reach significance.

\section{Arteries}

Rejection was commonly associated with an arteritis. In such cases mononuclear cells were either adherent to and infiltrating under the endothelial surface, or infiltrating the intima and media. Occasionally, massive mononuclear cell aggregates partly occluded me- 


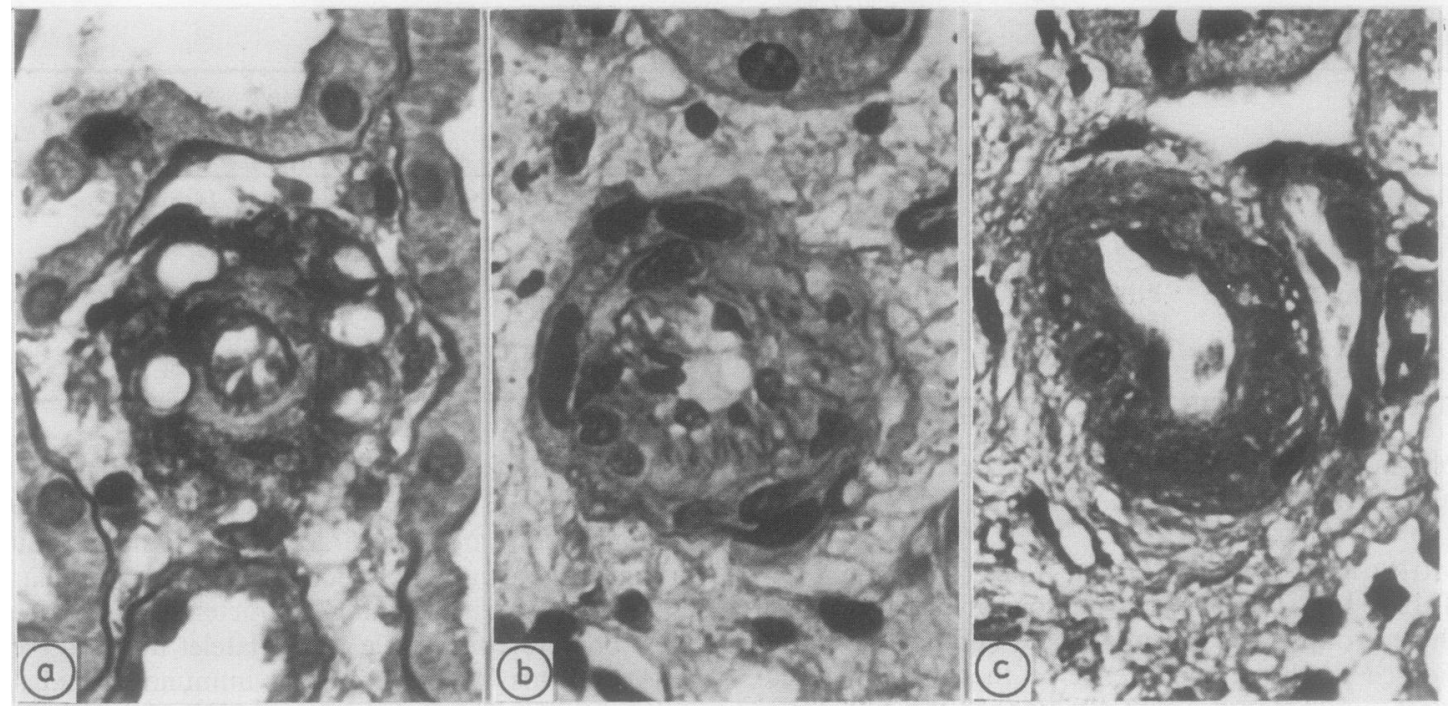

Fig. 2 Montage showing three arterioles $(a, b$, and $c)$. a) Arteriole is constricted and there is conspicuous medial cell vacuolisation. b) Arteriole is constricted and lumen is narrowed further by prominent endothelial cells. c) Hyalinosis of full thickness of arteriolar wall. (Periodic acid Schiff.) $\times 510$.

dium sized arteries. In severe cases there was fibrinoid necrosis of the media.

\section{Interstitium}

The tubules and interstitium should not be regarded as separate entities, but several comments can be made about the interstitium. Diffuse infiltration was indicative of rejection. Twenty of 21 biopsies that showed either moderate or severe (score 2 or more), diffuse, or focal and diffuse infiltration were associated with rejection. Similarly, all those who had interstitial haemorrhage were rejecting.

Six biopsies (two stable, four toxic) contained no mononuclear cell infiltration, in a further three biopsies (two stable, one toxic) there was a minimal cellular infiltration associated with interstitial fibrosis. Of the remainder, the infiltrates were typically focal. Focal infiltrates could be large and multiple, even in

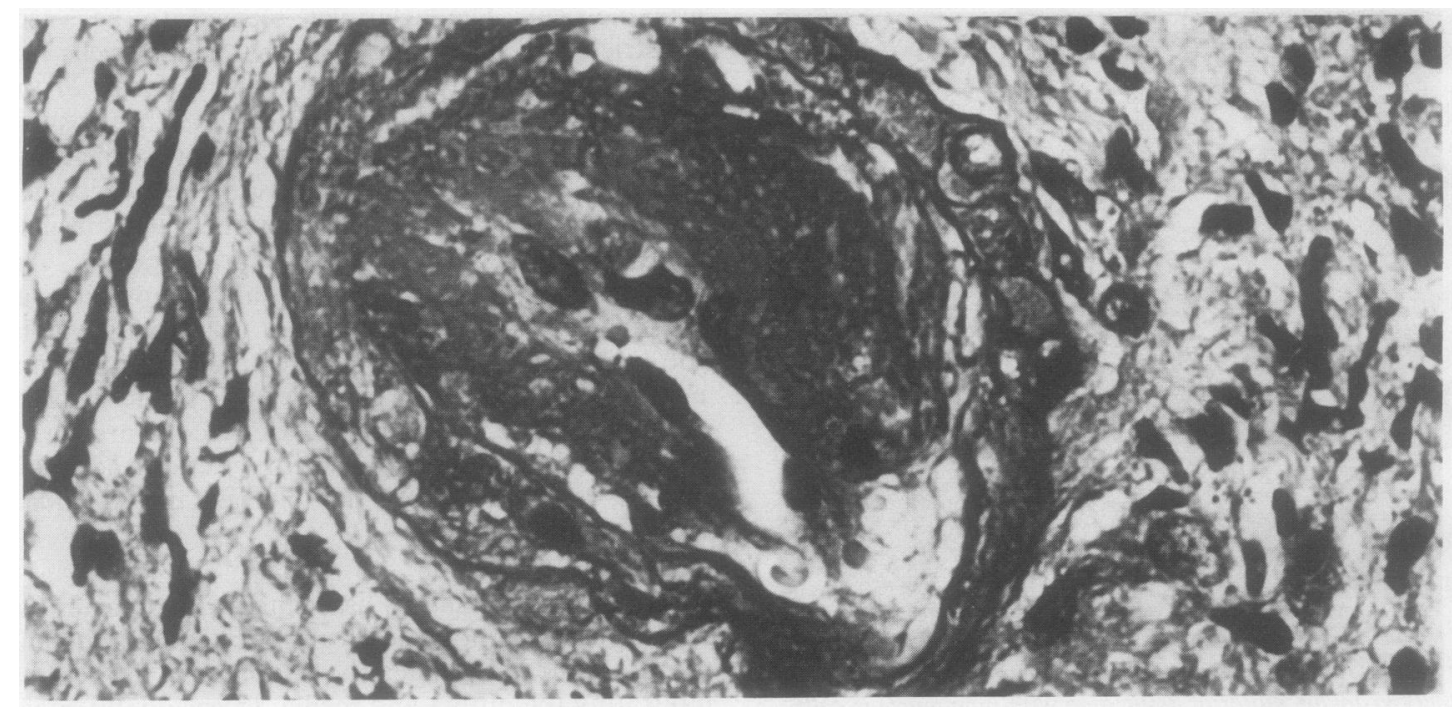

Fig. 3 Gross hyalinosis of vessel wall, with intimal expansion leading to stenosis of lumen. (Periodic acid Schiff.) $\times 510$. 
grafts with good stable function. Nevertheless, such infiltrates were often associated with the destruction of several tubules.

We also examined biopsies for "tubulitis," in which the mononuclear cells between tubules were still confined to the peritubular capillaries. This feature was recorded only when it affected at least $10 \%$ of tubules. In every instance the biopsies showed additional focal or diffuse infiltration.

\section{Tubules}

We did not find any aspect of tubular morphology helpful in the differential diagnosis.

\section{DIFFERENTIAL DIAGNOSIS}

Rejection We found that the histological diagnosis of rejection could always be made correctly. All biopsies classified by the response to treatment as "rejection" showed either diffuse interstitial mononuclear cell infiltrate and oedema, and sometimes haemorrhage, or arteritis, or a combination. Glomeruli showing a moderate or severe increase in mononuclear cells were exclusively found in those rejecting (12 of 35).

Cyclosporin nephrotoxicity Arteriolar lesions were prominent in this group. The mean age of all the donors whose kidney(s) showed moderate hyalinosis (score 2 or more) at any point was 32 years, which was precisely the same age as those with mild or no hyalinosis. The incidence of cardiovascular deaths in the donors was also the same in both these groups.

Stable function There was a high incidence of abnormal morphological features in this group, and there were no important differences between them and the toxicity group. It is clear, however, that in retrospect many who were stable had varying degrees of nephrotoxicity, as judged by subsequent improvement in function with scheduled reductions in the dose of cyclosporin.

Biopsies omitted from study Most of these patients, in retrospect, were clearly nephrotoxic. These included all seven who had a deterioration in function after a routine biopsy, all five who did not respond to (an inadequate) reduction in cyclosporin, and nine of 12 who did not respond to methylprednisolone. None of these 21 biopsies showed a diffuse infiltration, 15 showed hyalinosis, and two had glomerular thrombi.

\section{Discussion}

With our cyclosporin and prednisolone regimen we achieved excellent results both in graft survival and in the renal function of those surviving grafts.

Studies both in man and experimental animals have shown that allografts with normal function may be infiltrated by foci of mononuclear cells. ${ }^{41011}$ This was a striking feature of biopsies from our patients with both nephrotoxicity and stable function. The importance and origin of the focal infiltrates is not known, but they are not associated with rejection. In our study we may have overdiagnosed rejection, even in retrospect, but we did not miss the diagnosis, if one accepts that reducing the dose of cyclosporin during rejection would make rejection worse.

In contrast, a diffuse interstitial infiltration was strongly associated with rejection both in grafts with delayed function and those already functioning. Two important factors must be considered, however, in the differential diagnosis of rejection in non-functioning kidneys. First, in patients treated with azathioprine delayed allograft function attributed to "acute tubular necrosis" may be associated with a prominent cellular infiltrate, particularly near the corticomedullary junction, ${ }^{12}$ and care must be taken in analysing biopsies with limited areas of cortex. Whether patients treated with cyclosporin behave similarly is not known. Secondly, in contrast, the attribution of cellular infiltrate as part of the syndrome of acute tubular necrosis may possibly be inaccurate; cellular infiltrate is not a prominent early feature of acute tubular necrosis in native kidneys, ${ }^{13}$ and rejection is itself a cause of acute tubular necrosis. In some kidneys recovery of function may be delayed by rejection, which is then overcome as the immunosuppressive effect of cyclosporin increases. The similarity of the histological changes found in kidneys diagnosed as rejection during delayed function compared with rejection episodes in kidneys already functioning supports the concept that these nonfunctioning kidneys persisted in oliguria because of rejection during postischaemic acute tubular necrosis.

The mean time of the first biopsy after transplantation was only 4.4 days in non-functioning grafts, and this may reflect the number of patients in this study who were either highly sensitised or who were receiving second or third grafts.

A vascular component to the rejection, as judged by arteritis and haemorrhage, was more common and more severe in those with non-function. The Canadian Transplant Study Group reported that 60 of 213 first grafts had delayed function and of these, 13 $(22 \%)$ never functioned, usually for immunological reasons. ${ }^{14}$ We recommend that all non-functioning kidneys should be biopsied by day five at the latest. A further problem in interpreting diffuse infiltration occurs in biopsies after the treatment for rejection, particularly if an earlier biopsy is not available for comparison, as there will obviously be residual damage and a varying degree of cellular infiltrate.

As this study analysed the differential diagnosis of rejection $v$ toxicity, the biopsies were obtained mainly 
in the first three months after transplantation. With our regimen, rejection was very unusual after 30 days, and only four biopsies were diagnosed as rejection after this time. Thus all the diffuse interstitial infiltrate that we saw was in biopsy specimens obtained in the first 30 days. We did not see late cases of diffuse infiltrate associated with deteriorating function.

The arteriolar changes that we detailed were first reported by Mihatsch et al. ${ }^{67}$ They described them as being similar to the changes seen in malignant hypertension or the haemolytic uraemic syndrome. The presence of these lesions, however, can be used only in the diagnosis of toxicity in the absence of active or previous vascular rejection. Vessel lesions may be of donor origin and should be interpreted with caution in kidneys from elderly or hypertensive donors.

Because of the different nature of the three events, the timing of the biopsies differed in the three groups. Rejection was uncommon after the first two weeks (median time of biopsy was seven days), and toxicity was relatively uncommon in the first two weeks (median time 26 days). Some lesions such as vascular lesions could arise more often in the nephrotoxic biopsies because they might appear after allografting from other causes, and the nephrotoxic biopsies were taken later than those with rejection. We analysed separately all biopsy specimens obtained in the first 14 days and our conclusions do not differ from the full analysis. Moreover, in serial biopsies from patients with nephrotoxicity we saw vascular lesions progress. We do not believe that our conclusions regarding the blood vessels reflect an artefact of timing.

From studies on man and experimental animals it seems that cyclosporin may initiate or enhance vascular injury, and this effect may relate to its nephrotoxicity. A haemolytic uraemic syndrome may occur after both bone marrow ${ }^{15}$ and liver transplantation. ${ }^{16}$ Cyclosporin greatly enhances the vascular injury that occurs in experimental acute serum sickness in rabbits, ${ }^{17}$ and accelerates arteriolosclerosis in the spontaneously hypertensive rat. ${ }^{18}$ These interactions of cyclosporin suggest that it could, particularly in toxic doses, enhance the inflammatory component of vascular rejection. We have already reported that high doses of cyclosporin may be associated with glomerular capillary thrombi in the allograft. ${ }^{9}$ This lesion was seen in grafts treated with cyclosporin that were rejecting, but all such cases occurred in the first 30 days and were associated with high cyclosporin concentrations. When thrombi are seen in grafts that do not show evidence of rejection we suggest that they are indicative of toxicity.

As a control group we biopsied patients with stable renal function. In retrospect, their plasma creatinine concentrations were inappropriately high and as their dose of cyclosporin was reduced according to sched- ule, their cyclosporin and creatinine concentrations fell, indicating that they probably had had a degree of nephrotoxicity. This may explain why we found no important differences in morphology between this group and the nephrotoxic group.

It is likely that all grafts suffer some degree of nephrotoxicity, but that this is mild and compatible with adequate or even good renal function in the short term. It is important to know that such well functioning grafts may contain multiple foci of mononuclear cell infiltrates. Prolonged dysfunction due to nephrotoxicity may be associated with vascular injury. If this is not recognised then the vascular injury will lead to ischaemic damage, which is manifested by tubular atrophy and interstitial fibrosis.

\section{References}

${ }^{1}$ Calne RY, White DJG, Thiru S, et al. Cyclosporin A in patients receiving renal allografts from cadaver donors. Lancet 1978;ii:1323-7.

${ }^{2}$ Cyclosporin $\mathrm{A}$ as sole immunosuppressive agent in recipients of kidney allografts from cadaver donors: preliminary results of a European multicentre trial. Lancet 1982;ii:57-60.

${ }^{3}$ Strom TB, Loertscher R. Cyclosporine-induced nephrotoxicity. New Engl J Med 1984;311:728-9.

${ }^{4} \mathrm{~K}$ lintmalm G, Bergstrand A, Ringden O, et al. Graft biopsy for the differentiation between nephrotoxicity and rejection in cyclosporin A treated renal allograft recipients. Transplant Proc 1983;15:493-6.

${ }^{5}$ Sibley RK, Rynasiewicz J, Ferguson RM, et al. Morphology of cyclosporine nephrotoxicity and acute rejection in patients immunosuppressed with cyclosporine and prednisolone. Surgery 1983;94:225-34.

${ }^{6}$ Mihatsch MJ, Thiel G, Spichtin HP, et al. Morphological findings in kidney transplants after treatment with cyclosporine. Transplant Proc 1983;15:2821-35.

7 Thiel G, Harder F, Loertscher R, et al. Cyclosporin A used alone or in combination with low-dose steroids in cadaveric renal transplantation. Klin Wochenschr 1983;61:991-1000.

${ }^{8}$ Taube DH, Neild GH, Williams DG, et al. Differentiation between allograft rejection and cyclosporin nephrotoxicity in renal allograft recipients. Lancet 1985;ii:171-4.

${ }^{9}$ Neild GH, Reuben R, Hartley RB, Cameron JS. Glomerular thrombi in renal allografts associated with cyclosporin therapy. J Clin Pathol 1985;38:253-8.

${ }^{10}$ Homan WP, Fabre JW, Williams KA, Millard PR, Morris PJ. Studies on the immunosuppressive properties of cyclosporin $A$ in rats receiving renal allografts. Transplantation 1980;29:361-5.

${ }^{11}$ McWhinnie DL, Thompson JF, Taylor HM, et al. Leucocyte infiltration patterns in renal allografts assessed by immunoperoxidase staining of 245 sequential biopsies. Transplant Proc 1985;17:560-1.

${ }^{12}$ Burdick JF, Beschorner WE, Smith WJ, et al. Characteristics of early routine renal allograft biopsies. Transplantation 1984; 38:679-84.

${ }^{13}$ Solez K, Morel-Maroger L, Sraer J-D. The morphology of "acute tubular necrosis" in man. Medicine 1979;58:362-76.

${ }^{14}$ Belitsky P, and the Canadian Transplant Study Group. Initial non-function of cyclosporine-treated cadaver renal allografts preserved by simple cold storage. Transplant Proc 1985; 27:1485-8. 
15 Shulman H, Striker G, Deeg HJ, Kennedy M, Storb R, Thomas ED. Nephrotoxicity of cyclosporin A after allogeneic marrow transplantation: glomerular thromboses and tubular injury. New Engl J Med 1981;305:1392-5.

${ }^{16}$ Bonser RS, Adu D, Franklin I, McMaster P. Cyclosporin-induced haemolytic uraemic syndrome in liver allograft recipient. Lancet 1984;ii:1337.

${ }^{17}$ Neild GH, Ivory K, Williams DG. Glomerular thrombosis and cortical infarction in cyclosporin-treated rabbits with acute serum sickness. Br J Exp Pathol 1983;65:133-44.

${ }^{18}$ Ryffel B, Siegel H, Mueller A-M, Hauser R, Mihatsch MJ. Nephrotoxicity of cyclosporine in spontaneously hypertensive rats. Transplant Proc 1985;27:1430-1.

Requests for reprints to: Dr GH Neild, St Philip's Hospital, Sheffield Street, London WC2A 2EX, England. 